\title{
Informe sobre el estado \\ del clima de España 2020
}

\section{Resumen ejecutivo}

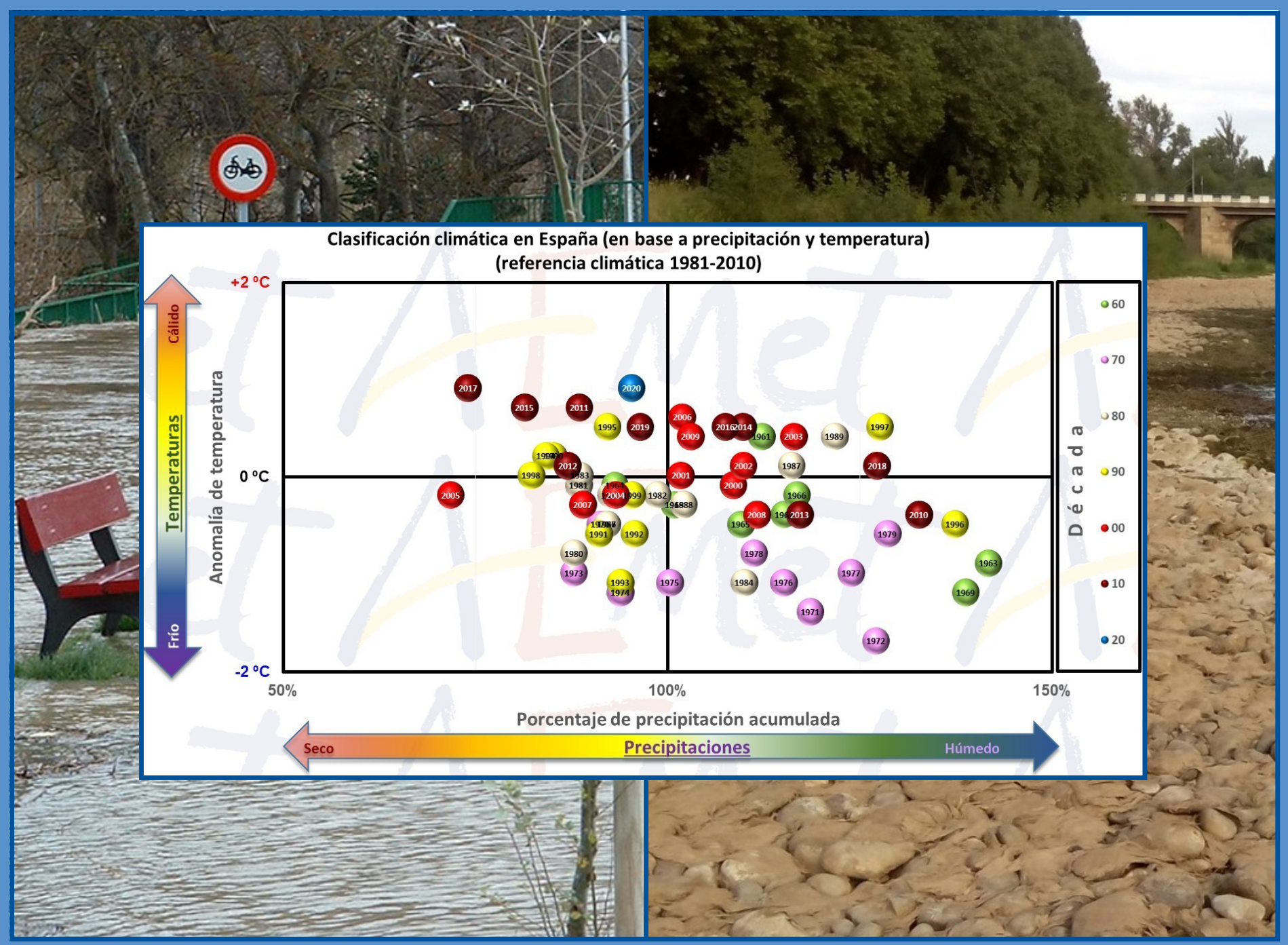

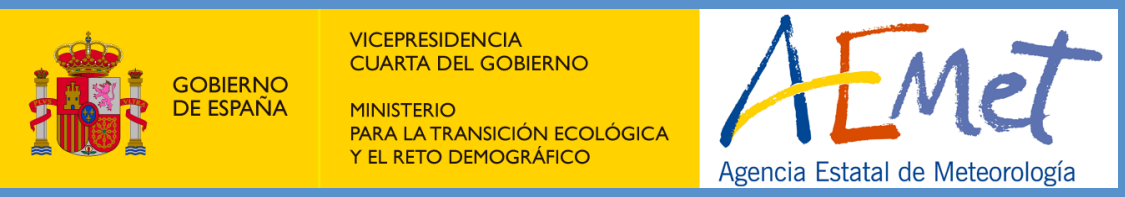




\section{Edita:}

(C) Ministerio para la Transición Ecológica y el Reto Demográfico Agencia Estatal de Meteorología

Madrid, 2021

Catálogo de Publicaciones de la Administración General del Estado: https://cpage.mpr.gob.es/

NIPO: 666-21-003-9

https://doi.org/10.31978/666-21-003-9

Agencia Estatal de Meteorología (AEMET)

C/ Leonardo Prieto Castro, 8

28040 Madrid

http://www.aemet.es/

\section{@Aemet_Esp}

f https://www.facebook.com/AgenciaEstataldeMeteorologia 


\section{INTRODUCCIÓN}

El sistema climático global se está calentando, mayoritariamente como consecuencia de las actividades humanas, que provocan un aumento en la concentración de gases de efecto invernadero (GEI) en la atmósfera. El año 2020 fue uno de los tres años más cálidos a escala global desde que hay registros, Europa vivió su año más cálido en 2020 y lo mismo ocurrió en España, donde se trató del año más cálido desde el inicio de la serie en 1961, igualado con 2017.

$\mathrm{El}$ aumento de la temperatura desde la época preindustrial se cifra en alrededor de $1.2^{\circ} \mathrm{C}$ en el conjunto del planeta; próximo a $2.2^{\circ} \mathrm{C}$ en el continente europeo y ronda $1.7^{\circ} \mathrm{C}$ en España. En nuestro país, la mayor parte de ese incremento de temperatura $\left(1.3^{\circ} \mathrm{C}\right)$ se ha producido en los últimos 60 años.

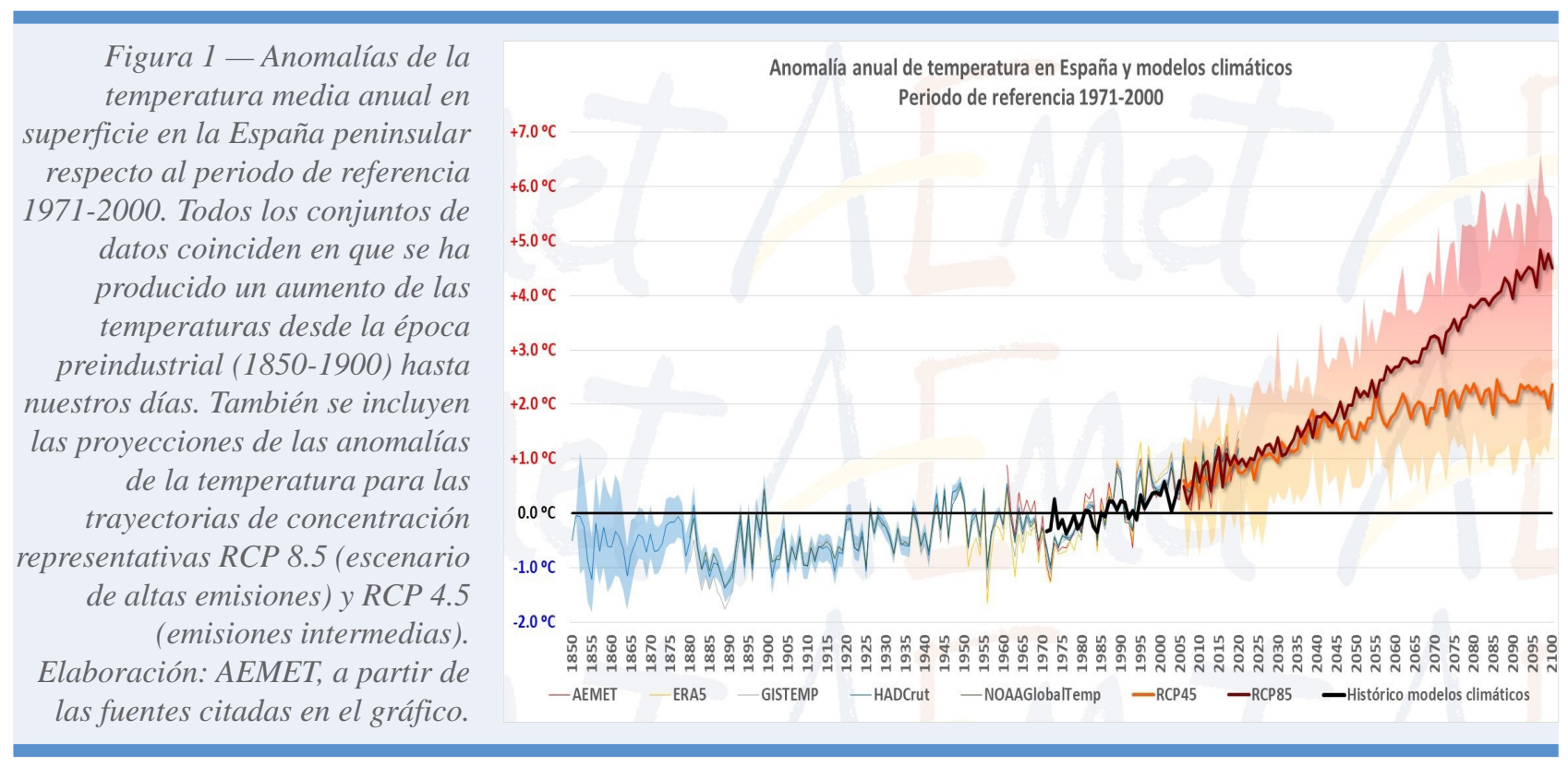

Los modelos climáticos han sido capaces de reproducir fidedignamente el aumento de temperatura en España entre 1971 y 2005; estos mismos modelos proyectan un aumento de la temperatura de unos $2{ }^{\circ} \mathrm{C}$ para fin de siglo con un escenario de emisiones intermedias y de alrededor de $5^{\circ} \mathrm{C}$ para un escenario de emisiones altas.

El calentamiento global lleva asociado un aumento de los fenómenos extremos, tales como olas de calor, lluvias torrenciales y sequías más intensas; subida del nivel del mar y acidificación de los océanos, y la disminución de las masas de hielo y nieve. Cobra especial relevancia, en España, el notable incremento del número y la duración de las olas de calor en la década más reciente, aspecto que supone un grave peligro para la salud humana: se estima que en el último quinquenio han fallecido cerca de 1800 personas al año por exceso de calor en verano según los datos del Instituto de Salud Carlos III. Paralelamente, se producen episodios de lluvias torrenciales muy intensos, como el asociado a la borrasca Gloria en enero de 2020, que dejó la mayor cantidad de precipitaciones sobre el conjunto del Mediterráneo español considerando tres días seguidos. 


\section{ESTADO DEL CLIMA GLOBAL Y DE EUROPA}

\section{TEMPERATURAS}

La temperatura media mundial en el año 2020 fue de aproximadamente $14.9^{\circ} \mathrm{C}$, es decir, $1.2^{\circ} \mathrm{C}$ superior a la de la época preindustrial. La temperatura de 2020 fue comparable a la de 2016, año más cálido en el registro, a pesar de que en buena parte de 2020 se produjo el fenómeno de La Niña, que tiende a disminuir la temperatura global. En 2016, en cambio, tuvo lugar un intenso fenómeno de El Niño, cuyo efecto es justamente el contrario: tiende a calentar el planeta. Los últimos seis años fueron excepcionalmente cálidos. Tanto el quinquenio más reciente como la última década han sido los de mayor temperatura media registrada.

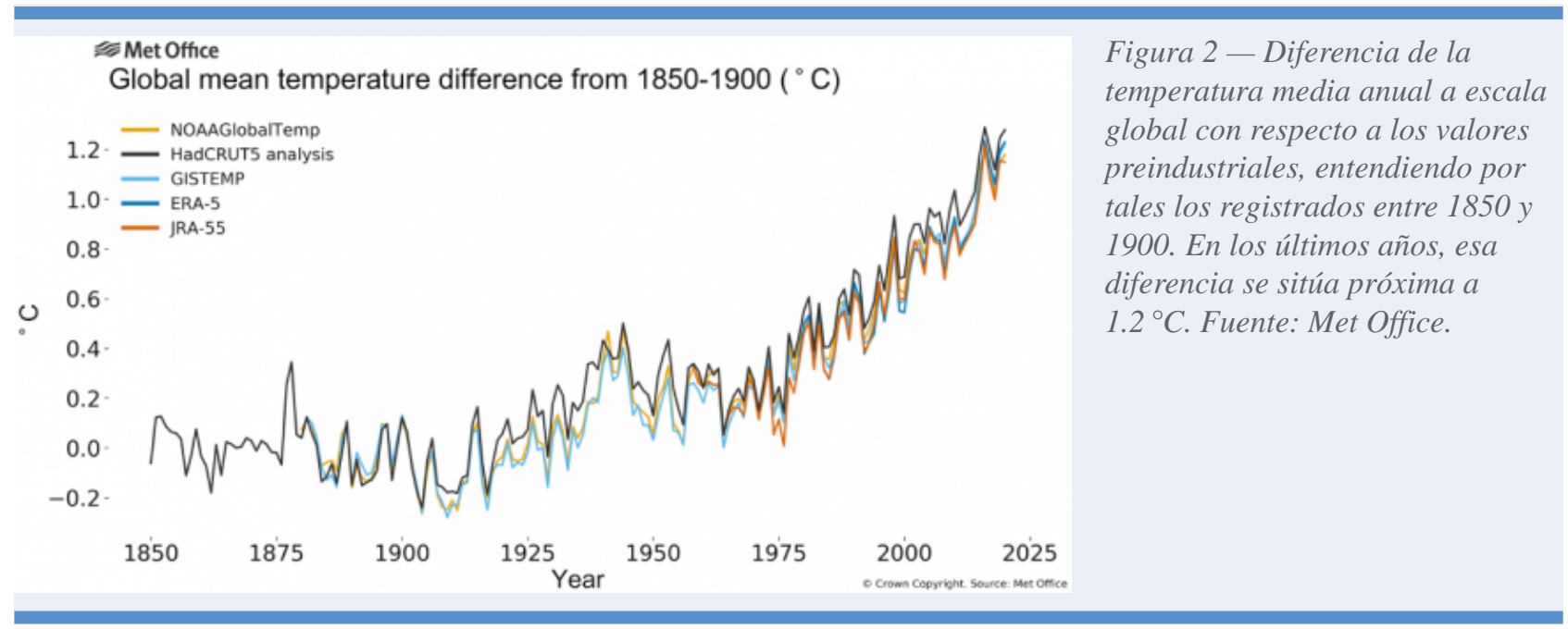

También en el continente europeo 2020 fue el año más cálido registrado. La temperatura media estuvo $0.4^{\circ} \mathrm{C}$ por encima del anterior año más cálido, que fue 2019 y fue $1.6^{\circ} \mathrm{C}$ superior a la del periodo de referencia 1981-2010. En el viejo continente, los cuatro años más cálidos de que se tiene constancia tuvieron lugar en la última década. El año 2020 fue excepcionalmente cálido en latitudes altas del hemisferio norte: amplias zonas del Ártico y norte de Siberia tuvieron temperaturas medias $3^{\circ} \mathrm{C}$ superiores al valor normal, y en algunos lugares las anomalías llegaron hasta los $6^{\circ} \mathrm{C}$.

Surface air temperature anomaly for January 2020 to December 2020

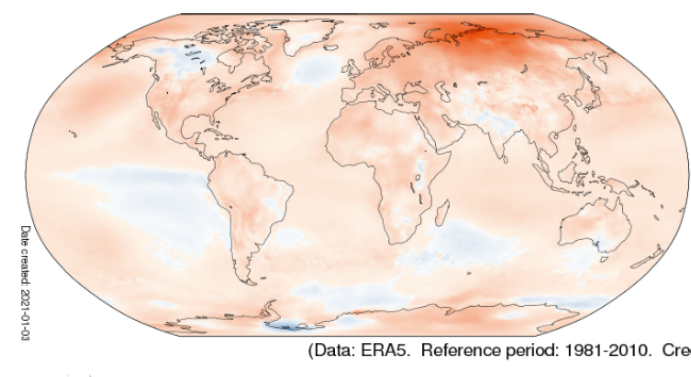

Copernicus

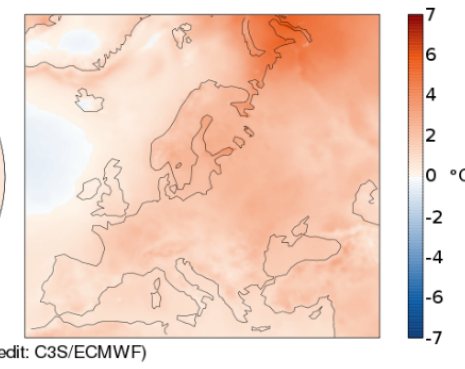

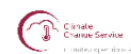

Figura 3 - Anomalía de temperatura a escala global (izquierda) y europea (derecha) durante el año 2020. Los tonos rojos indican que el año fue más cálido de lo normal; los azules, más frío. Fuente: Copernicus Climate Change Service / ECMWF. 


\section{OCÉANOS, HIELO Y NIEVE}

Los océanos están absorbiendo la mayor parte de la energía acumulada en el sistema climático de la Tierra como consecuencia del aumento de las emisiones de gases de efecto invernadero, lo que se traduce en un calentamiento de las aguas y su expansión térmica. Así, la elevación del nivel medio del mar se cifra en unos $3.3 \mathrm{~mm}$ al año. La fusión de los hielos en Groenlandia y la Antártida está contribuyendo también al ascenso del nivel del mar en los últimos años. El aumento de los niveles de $\mathrm{CO}_{2}$ en la atmósfera también se manifiesta en los océanos, lo que lleva a su acidificación, con numerosos impactos en los ecosistemas marinos. En 2020, más del $80 \%$ de las aguas oceánicas experimentaron al menos una ola de calor marina, la mayoría de ellas (el $43 \%$ ) clasificadas como fuertes.

En cuanto a la criosfera, que comprende nieve, aguas congeladas, glaciares, capas de hielo y suelos congelados, desempeña un papel importante en el sistema climático de la Tierra y proporciona alguna de las señales más visibles del cambio climático: las capas de hielo de Groenlandia y la Antártida están perdiendo masa, al igual que los glaciares. El hielo marino ártico lleva décadas disminuyendo, mientras que en los últimos años se ha producido una reducción de la extensión del hielo marino antártico. La cobertura de nieve del hemisferio norte en primavera se está reduciendo y el permafrost (suelos congelados) se está fundiendo.

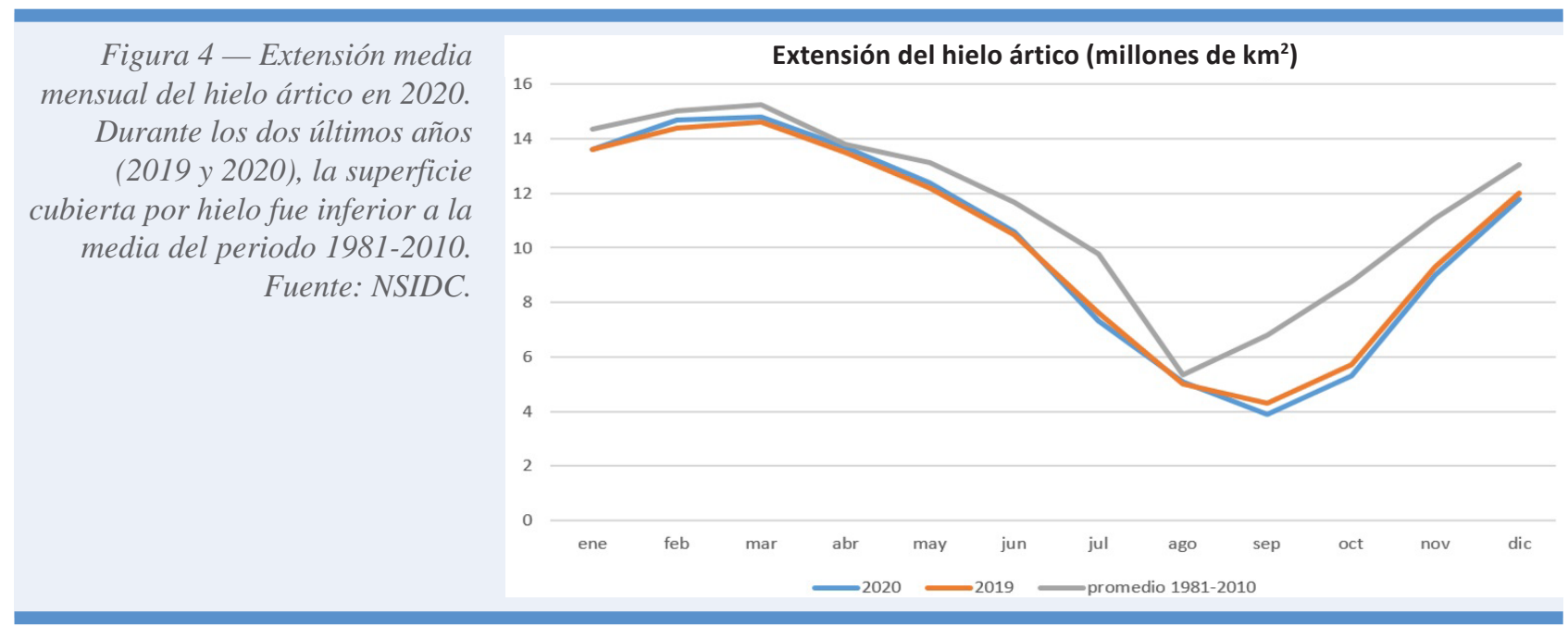

La extensión mínima de hielo ártico en el año 2020 tuvo lugar a mediados de septiembre, y fue la segunda más baja de la serie, tan solo por detrás de 2012. Además, en julio y octubre se batió el récord de menor extensión de hielo para estos meses desde que se iniciaron las medidas por satélite, hace 42 años.

\section{GASES DE EFECTO INVERNADERO}

El calentamiento global es el resultado de desequilibrios en el balance energético de la Tierra, que son causados por procesos y agentes naturales y antropogénicos. Entre estos últimos, destaca la emisión de gases de efecto invernadero: son los agentes que más han contribuido al calentamiento del planeta y, entre todos, destaca el dióxido de carbono $\left(\mathrm{CO}_{2}\right)$. Las concentraciones de $\mathrm{CO}_{2}$ alcanzaron un máximo mundial sin precedentes, con un valor promedio de 
413.1 ppm (partes por millón), aproximadamente 2.3 ppm más que en 2019. La tasa de crecimiento en 2020 fue, sin embargo, menor que la de 2019, cifrada en 2.5 ppm.

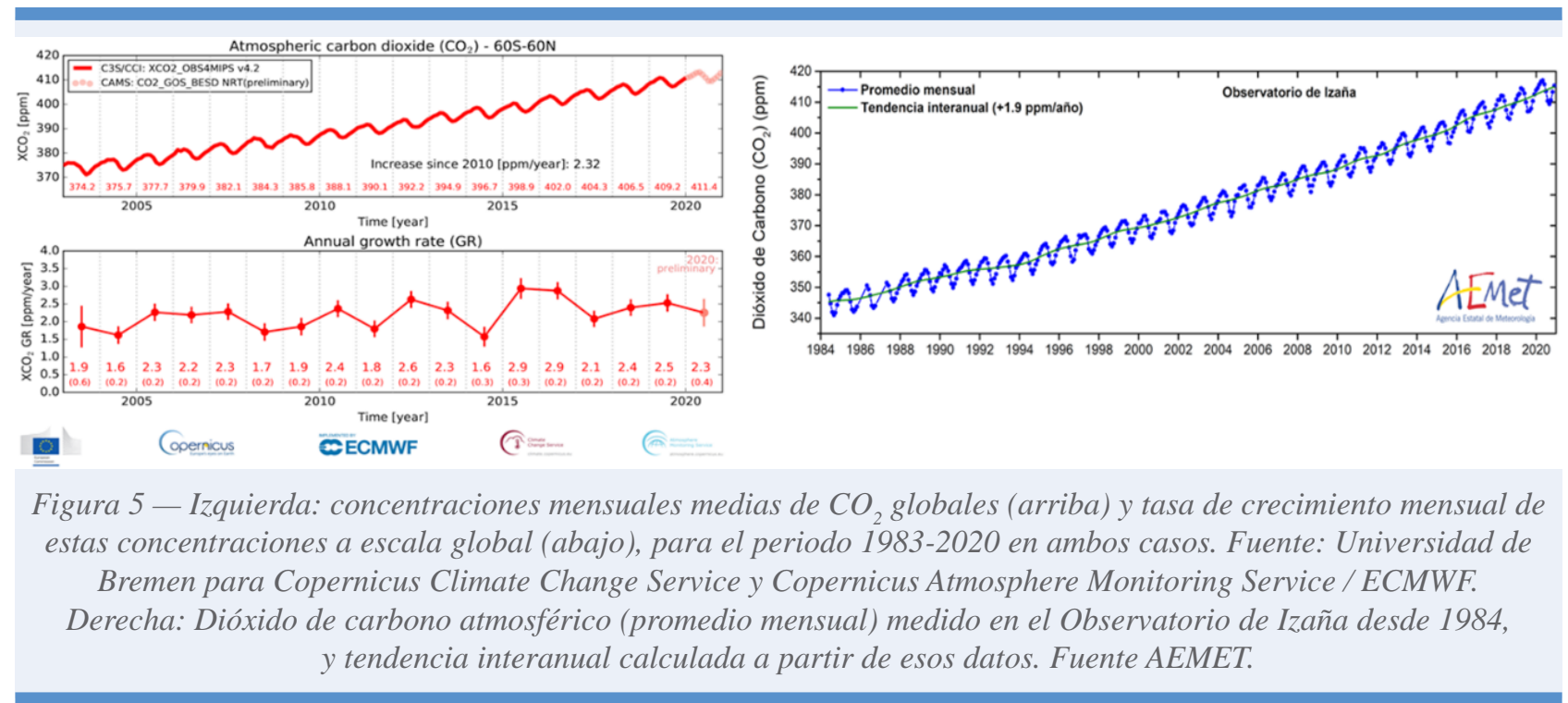

En el observatorio de Vigilancia Atmosférica Global de Izaña (Tenerife) se alcanzaron en abril de 2020 alrededor de $418.7 \mathrm{ppm}$ de concentración media diaria de $\mathrm{CO}_{2}$. Este valor, además de suponer un récord histórico de la serie, se sitúa en $2.2 \mathrm{ppm}$ por encima de lo alcanzado en 2019. El crecimiento interanual entre 2019 y 2020 fue superior al del promedio, cifrado en $1.9 \mathrm{ppm}$ al año desde que comenzaron las mediciones en 1984. Otros importantes gases de efecto invernadero cuya concentración se mide en Izaña, como el metano $\left(\mathrm{CH}_{4}\right)$, el óxido nitroso $\left(\mathrm{N}_{2} \mathrm{O}\right)$ y el hexafluoruro de azufre $\left(\mathrm{SF}_{6}\right)$ también alcanzaron su valor más alto de la serie a lo largo de 2020.

\section{PRECIPITACIONES, ANOMALÍAS Y FENÓMENOS EXTREMOS}

Uno de los fenómenos meteorológicos extremos con mayor impacto son las lluvias intensas que dan lugar a inundaciones, en especial cuando ocupan zonas extensas. Es lo que ocurrió en 2020 en el Cuerno de África y el Sahel, así como en el sureste asiático, región donde la actividad monzónica fue muy intensa. Por otro lado, las sequías afectaron a amplias zonas de América del norte, donde se produjeron importantes incendios forestales favorecidos también por las altas temperaturas, y a muchas regiones del hemisferio sur.

En Verkhoyansk, ciudad rusa situada por encima del círculo polar, se alcanzaron $38^{\circ} \mathrm{C}$ en junio, el valor más alto jamás alcanzado en esas latitudes. También hubo temporales de frío y nieve, algunos tempranamente, como los que ocurrieron en América del Norte en septiembre. Hay que destacar, por su carácter extraordinario, la temporada de huracanes en el Atlántico norte: se formaron 30 tormentas tropicales con nombre, de las que 13 alcanzaron categoría de huracán, seis de ellos de categoría 3 o más. Fue la temporada más activa desde que hay registros.

En la infografía de la figura 6 se señalan algunos de los fenómenos meteorológicos y climáticos más extremos que ocurrieron en nuestro planeta a lo largo de 2020: 


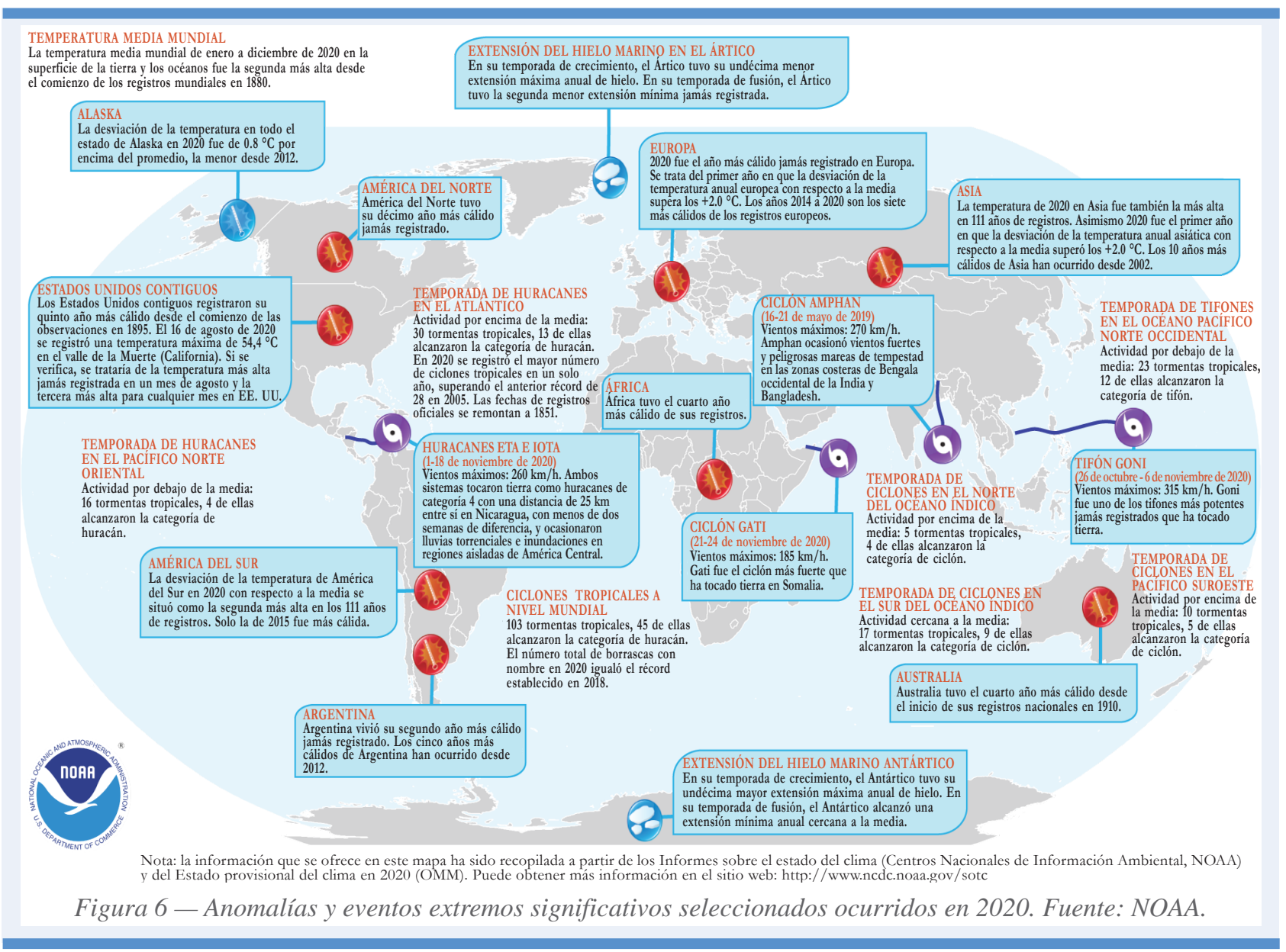

\section{ESTADO DEL CLIMA DE ESPAÑA}

El año 2020 fue, junto con 2017, el más cálido de la serie histórica, cuyo comienzo se sitúa en 1961. En cuanto a las precipitaciones, aunque estas quedaron ligeramente por debajo de la media, puede considerarse un año normal. El año estuvo salpicado por fenómenos extremos: hubo tres olas de calor, episodios de lluvias intensas y una gran entrada de polvo en suspensión en Canarias.

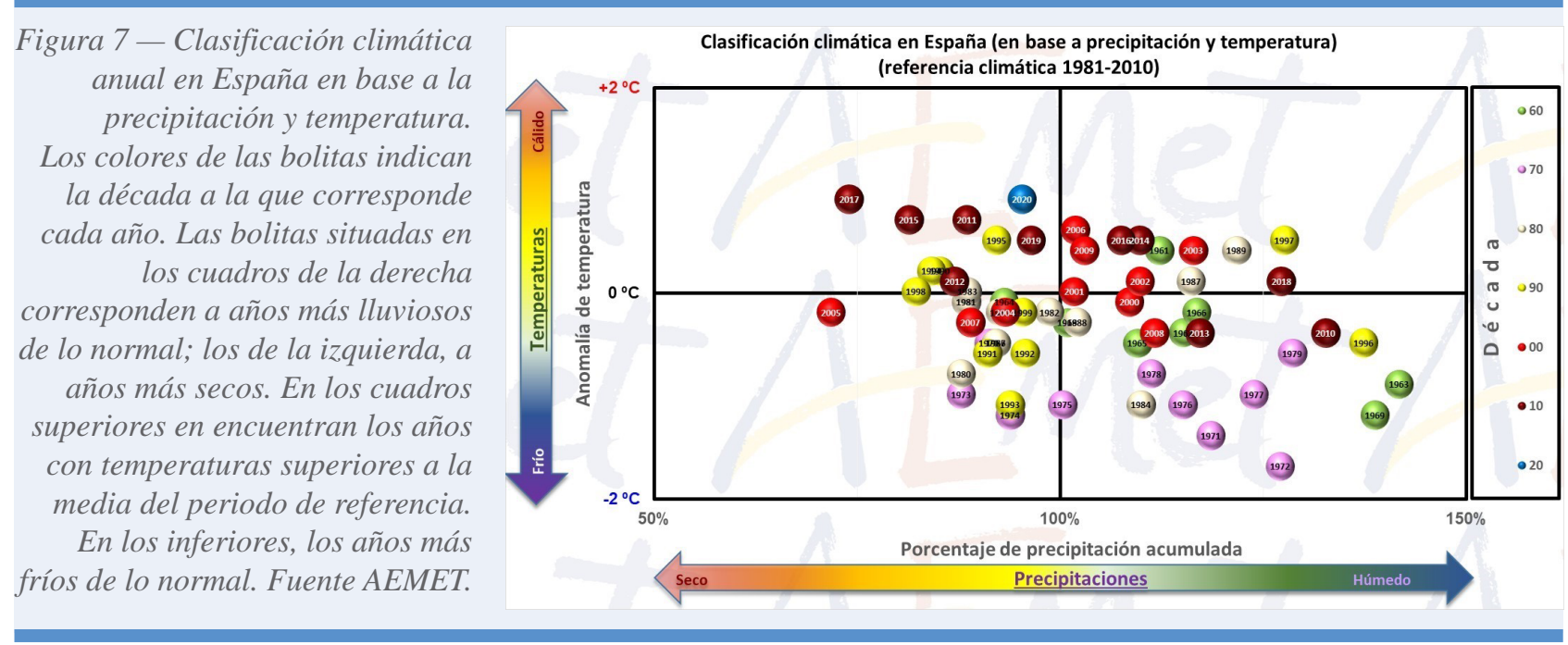




\section{TEMPERATURAS}

2020 fue un año extremadamente cálido en España: la temperatura media, de $14.8^{\circ} \mathrm{C}$, superó en $1{ }^{\circ} \mathrm{C}$ al promedio anual del periodo de referencia 1981-2010. Se trató del año más cálido de la serie histórica junto con 2017, y es muy destacable que ocho de los diez años más cálidos en nuestro país desde 1961 se hayan registrado en el siglo XXI y siete de ellos en la década 2011-2020.

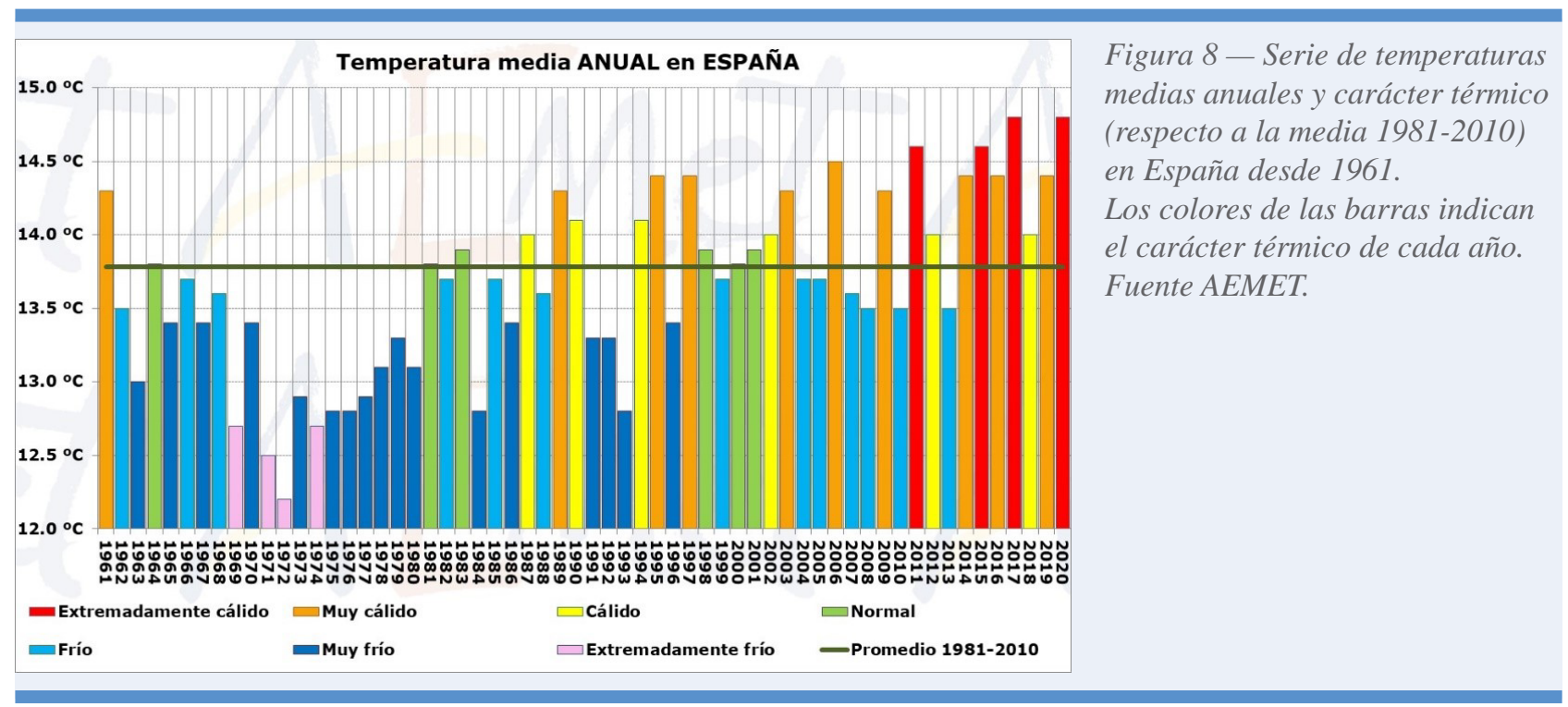

Hubo uniformidad espacial en cuanto a las altas temperaturas, ya que el año fue muy cálido o extremadamente cálido en todo el territorio nacional. Dos de cada tres días tuvieron temperaturas por encima de lo normal, frente a solo un tercio que fueron más bajas. Por meses, tan solo hubo dos meses fríos; el resto, tuvo temperaturas más altas de lo normal, especialmente febrero (el más cálido de la serie) y mayo (el segundo más cálido). En consonancia con estas altas temperaturas, en 2020 no hubo ninguna ola de frío. Por el contrario, se registraron tres olas de calor, una de las cuales, la vivida entre los días 25 de julio y 2 de agosto, fue la tercera más larga desde 1975.

En un clima más cálido, es de esperar que los récords correspondientes a temperaturas altas (récords de calor) sean superiores a los récords de temperaturas bajas (récords de frío). Así se pone de manifiesto si se analizan los récords diarios de temperaturas altas y bajas en la España peninsular desde 1950 hasta 2020: durante los últimos 30 años, el número real de récords diarios de temperaturas altas es mucho mayor que el que cabría esperar en un clima que no se estuviese calentando, y lo contrario ocurre con el número de récords diarios de temperaturas bajas: es mucho menor que el valor teórico. En la última década, el número de récords de calor es prácticamente once veces superior al de récords de frío. En un clima estable, sin calentamiento, ambos tipos de récord deberían haber tenido un número similar. 
Figura 9-Número de récords diarios de temperatura por año en la España peninsular desde 1951.

Las barras rojas y azules representan los récords reales de

calor y frio, respectivamente, observados cada año.

Las curvas negras indican el número de récords anuales que cabría esperar en un clima que no se estuviese calentando.

El primer año todos los días son récord, porque hay un único registro para cada día, pero el número teórico de récords desciende cada año al incorporarse nuevos registros diarios.

Se observa cómo en los últimos años el número de récords de calor observado supera ampliamente al número teórico, y lo contrario ocurre con los récords de frío. Fuente: AEMET.

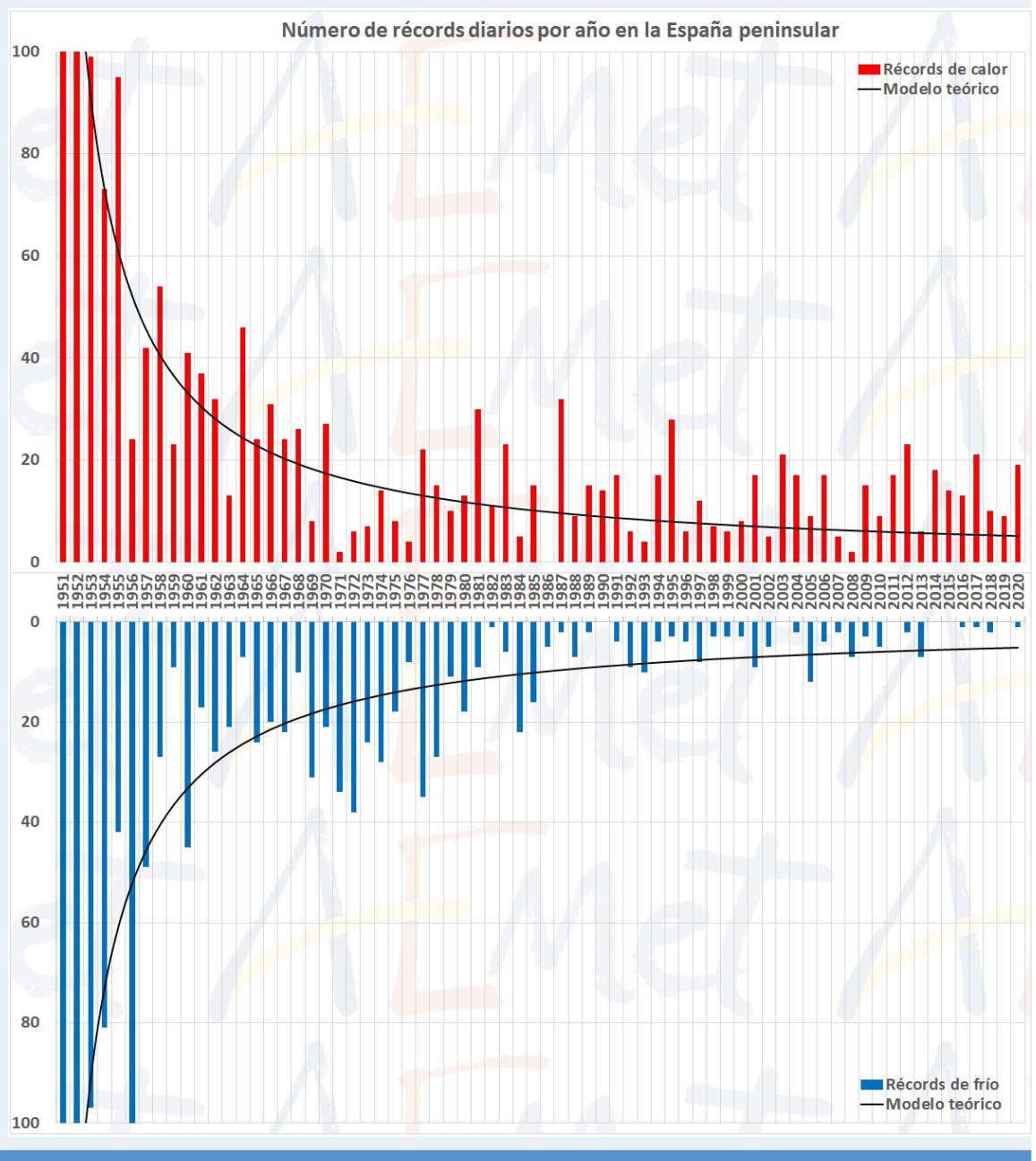

\section{TEMPERATURA SUPERFICIAL DEL AGUA DEL MAR}

Un parámetro para tener en cuenta en el análisis del clima de un país como España, cuyo territorio está mayoritariamente enclavado en una península y consta de dos importantes archipiélagos, es la temperatura superficial del agua del mar. En 2020, todas las zonas costeras y marítimas colindantes con el territorio español tuvieron temperaturas superiores a lo normal, salvo en el litoral de la fachada atlántica gallega, donde hubo zonas con temperaturas inferiores al valor promedio. Las mayores anomalías de temperatura se registraron en las aguas situadas entre las costas de Barcelona, Tarragona y norte de Baleares.

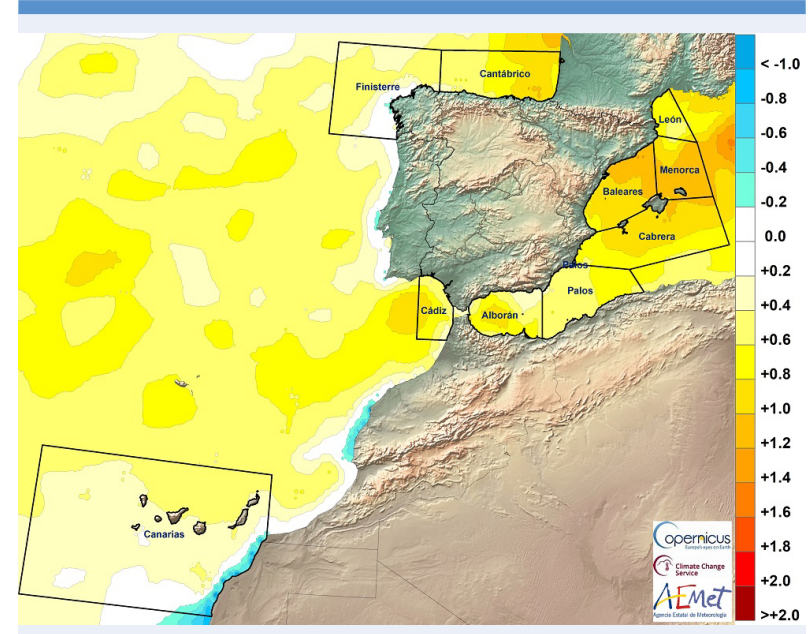

Figura 10 - Anomalía de la temperatura superficial del agua del mar en 2020. Los tonos cálidos indican temperaturas superiores a lo normal.

Fuente: Copernicus/AEMET. 
Para el conjunto de las zonas marítimas circundantes a España, la temperatura superficial del agua del mar en el año 2020 estuvo $0.5^{\circ} \mathrm{C}$ por encima de lo normal y fue la segunda más alta de la serie (cuyo arranque tiene lugar en 1950), tan solo superada por la registrada en 2017. Al igual que lo que ocurre con la temperatura del aire, se está produciendo en las últimas décadas un aumento de la temperatura del agua del mar, menos acusado que en el caso de la atmósfera por la mayor inercia térmica del agua.

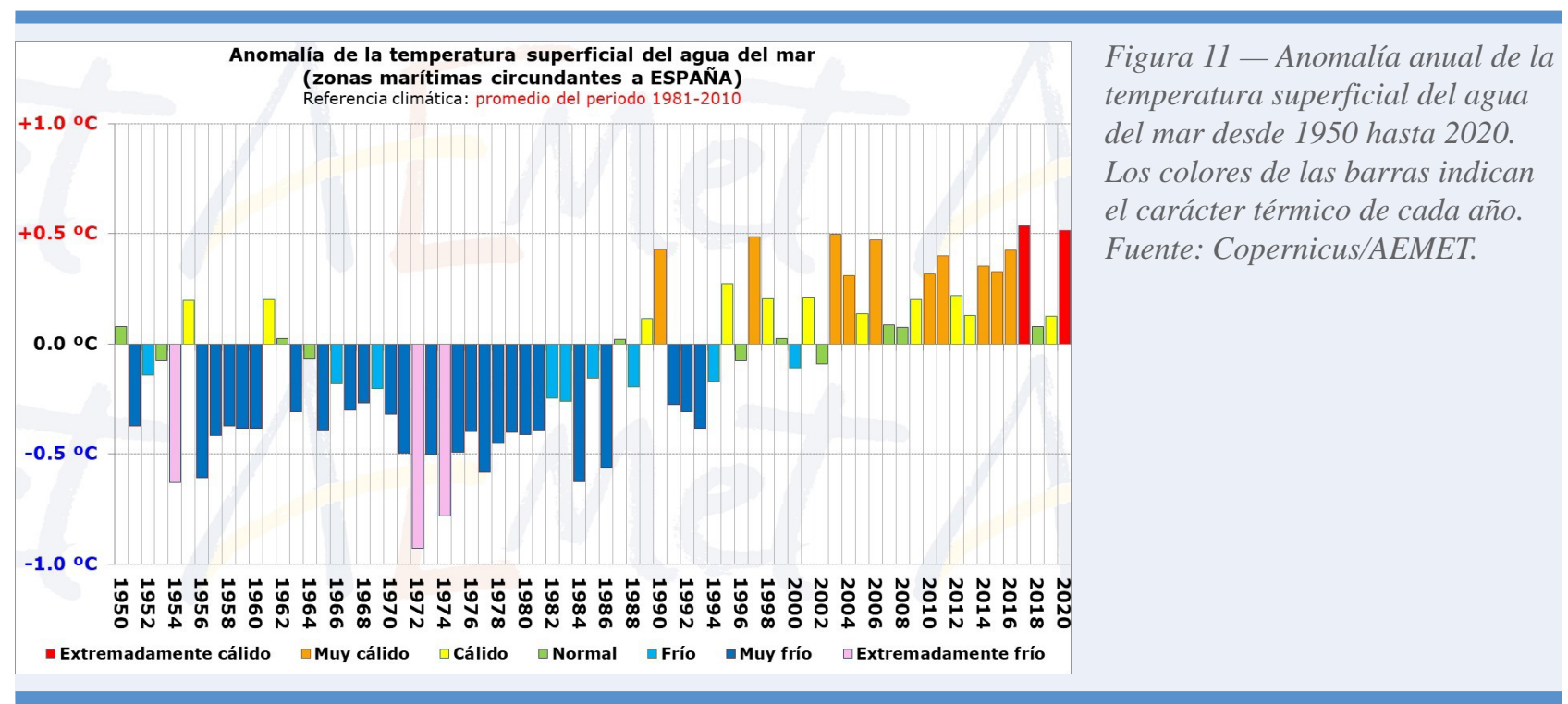

\section{PRECIPITACIONES}

El año 2020 fue normal en cuanto a precipitaciones. El acumulado total quedó ligeramente por debajo del valor promedio anual, en torno a un $6 \%$. Fue el octavo año más seco del siglo XXI y el vigesimocuarto desde el comienzo de la serie en 1961. Por zonas, el año fue más lluvioso de lo normal en la vertiente mediterránea peninsular, especialmente en el cuadrante nordeste, donde fue muy húmedo. Fue húmedo en amplias zonas del tercio oriental, centro y norte de la Península, mientras que fue seco o muy seco en el noroeste y suroeste. En
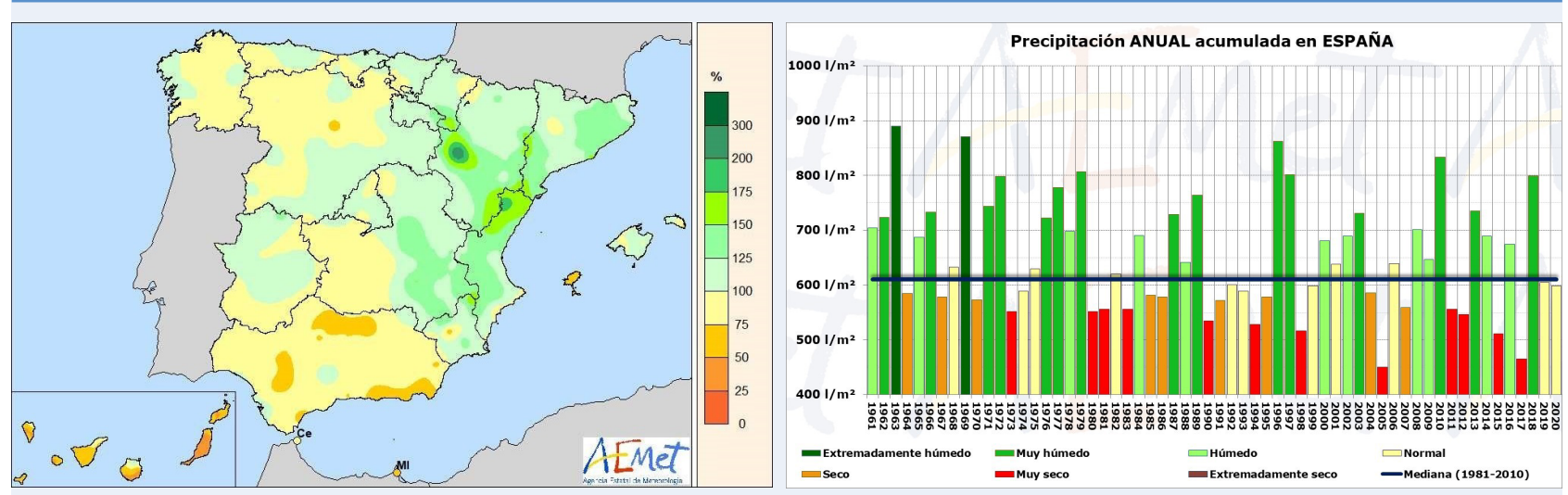

Figura 12 - Izquierda: porcentaje de la precipitación acumulada en 2020 respecto de la media 1981-2020. Derecha: evolución de la precipitación anual acumulada en España. Fuente: AEMET. 
Baleares fue seco en la Pitiusas y normal en el resto, mientras que en Canarias fue un año muy seco. La primavera fue la única estación con precipitaciones por encima de lo normal a lo largo del año; el resto registraron precipitaciones inferiores a la media. Destacaron febrero como el mes más seco y marzo como mes más lluvioso respecto a lo habitual para los respectivos meses.

En cuanto a episodios, cabe destacar el asociado a la borrasca Gloria, que afectó entre los días 18 y 25 de enero a la vertiente mediterránea peninsular y Baleares. Hubo acumulados superiores a los $400 \mathrm{l} / \mathrm{m}^{2}$ en zonas de montaña del norte de la provincia de Alicante. La borrasca Bárbara, entre el 19 y 22 de octubre, también dio lugar a acumulados de más de $400 \mathrm{l} / \mathrm{m}^{2}$, en este caso en el entorno del sistema Central. La borrasca Clement, entre finales de noviembre y comienzos de diciembre, dejó registros en puntos de Canarias próximos a los $501 / \mathrm{m}^{2}$, en un año sin temporales especialmente destacables en el archipiélago.

Un aspecto característico de las lluvias en España es su distribución irregular tanto espacial como temporalmente, por lo que resulta interesante analizar los periodos en los que a lo largo del año el déficit o falta de lluvias pueda haber provocado períodos de sequía meteorológica, es decir, aquella debida exclusivamente a la escasez de precipitaciones. Utilizando el índice de precipitación estandarizado (SPI), ampliamente aceptado para este fin, se deduce que la sequía meteorológica que se venía arrastrando a una escala temporal de seis meses desapareció en los primeros meses del año. Como a esta escala temporal el índice está relacionado con la actividad agrícola, se deduce que durante el año 2020 la disponibilidad de agua para los cultivos fue suficiente a nivel de la España peninsular.

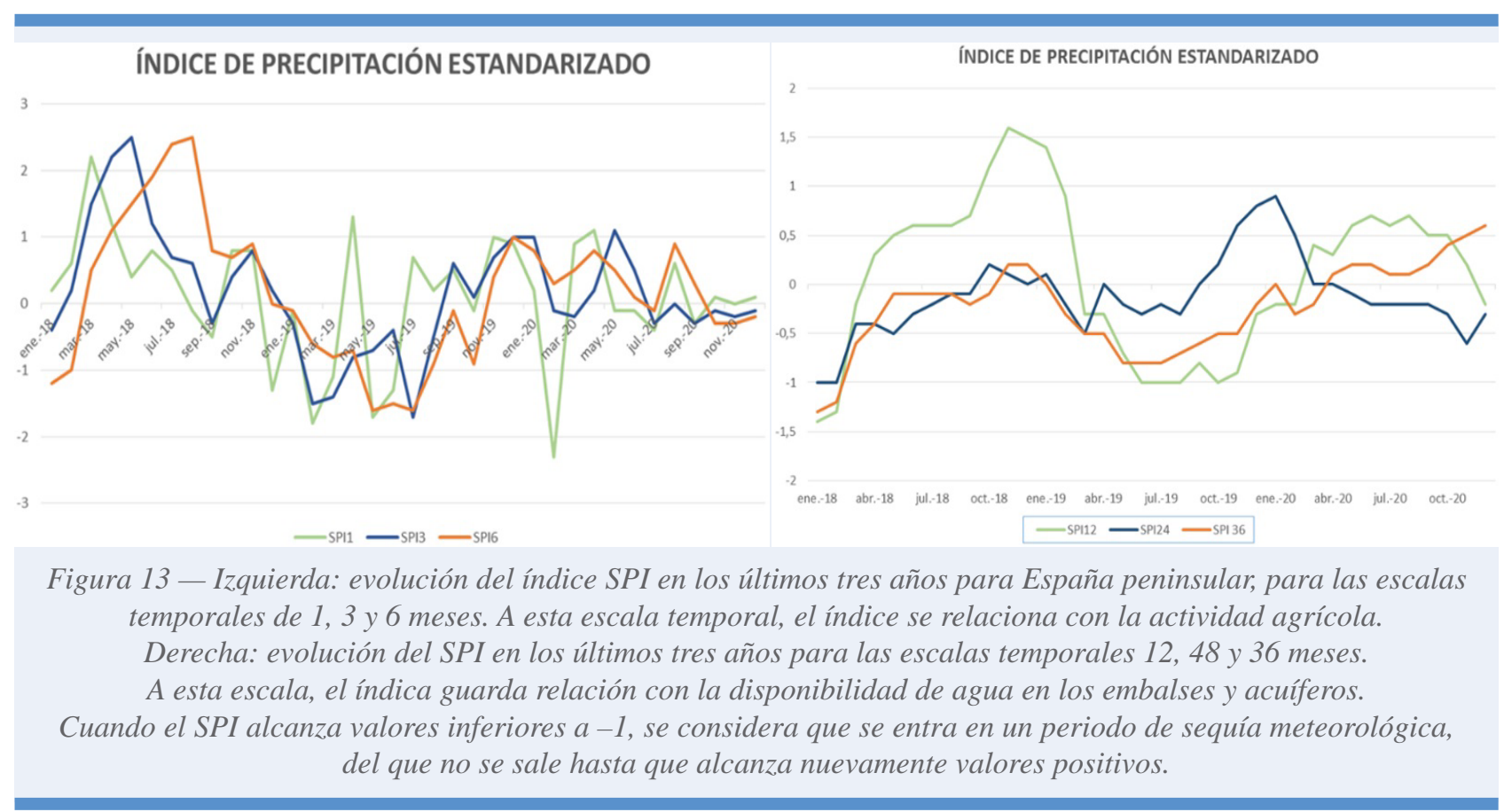

En cuanto al análisis de la sequía meteorológica en la escala temporal de un año, el periodo seco que había comenzado en junio de 2019 finalizó en marzo de 2020, manteniéndose el SPI en valores positivos ya durante la mayor parte del año. Esto, unido a que en la escala temporal de tres años el índice SPI también mostraba valores positivos a finales de 2020, indicaba una buena disponibilidad de agua para usos hidrológicos durante ese año. 


\section{INSOLACIÓN}

El número de horas de sol en el promedio de la superficie del territorio español ascendió a un total de 2842 en el año 2020. Es un valor muy próximo al normal, aunque hay que señalar que en puntos del extremo norte y de Andalucía oriental se trató de un año más soleado de lo habitual. Especialmente anómala fue la primavera por la escasez de horas de sol registrada en nuestro país, sobre todo en abril, al tiempo que países centroeuropeos informaban de una situación insólita por la gran cantidad de horas de sol que disfrutaron, en algunos casos de récord.

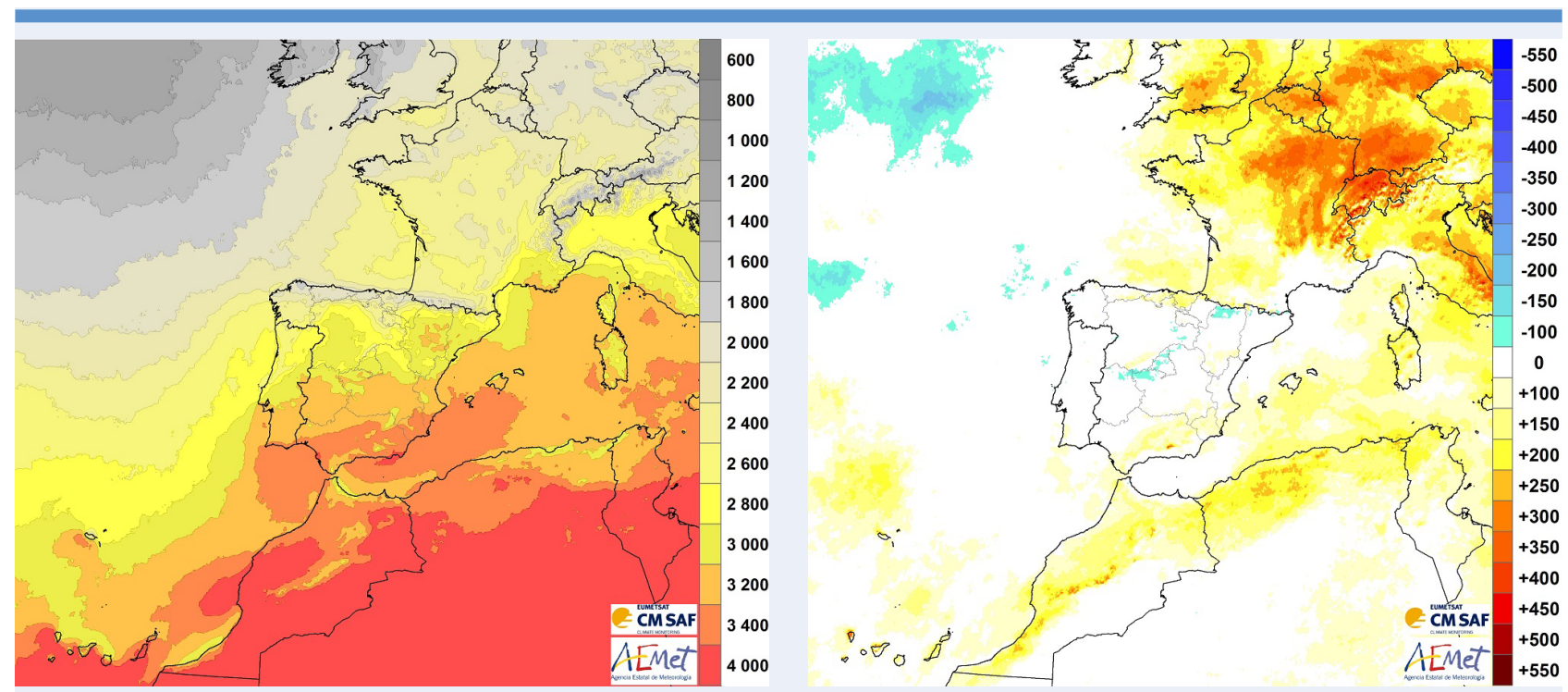

Figura 14 - Izquierda: número total de horas de sol registrado en 2020 en la península ibérica, Baleares, Europa occidental, Canarias y noroeste de África. Derecha: anomalía de horas de sol en las mismas áreas geográficas. Los tonos cálidos indican más horas de sol de lo normal. Fuente: CM SAF (EUMETSAT).

Esta escasez de horas de sol en España durante gran parte de la primavera se produjo a causa de una situación de altas presiones persistentes en el Atlántico nororiental, que favorecieron un constante tránsito de borrascas por el sur de la Península, con los consiguientes cielos más nublados que de costumbre.

\section{DESCARGAS ELÉCTRICAS Y DÍAS DE TORMENTA DURANTE 2020}

El número de descargas registradas a lo largo de 2020, tanto en la zona de la Península y Baleares como en la de Canarias, fue inferior al del promedio anual. De hecho, en Canarias los registros de 2020 fueron los más bajos de la serie. En enero, marzo y abril hubo tres episodios que dejaron una gran cantidad de descargas, muy superiores a las habituales en estos meses fríos. Por el contrario, septiembre y octubre, que suelen ser meses con una gran cantidad de tormentas en la vertiente mediterránea, fueron muy anómalos por la poca cantidad de descargas que se generaron, especialmente octubre, que fue el que menos descargas registró de toda la serie histórica. 


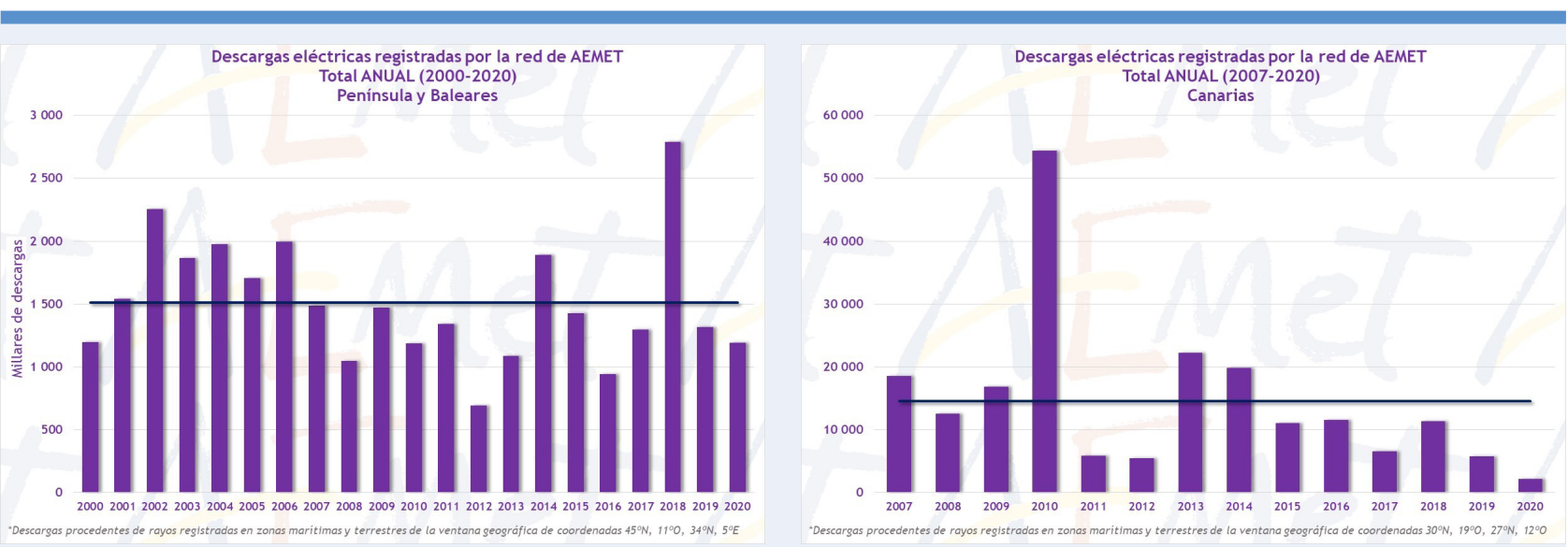

Figura 15 - Número de descargas eléctricas registradas por la red de AEMET en Península y Baleares entre 2000 y 2020 (izquierda), y Canarias entre 2007 y 2020 (derecha). Las líneas horizontales señalan, en cada gráfico, el valor medio anual del periodo. Fuente: AEMET.

A pesar del menor número de descargas eléctricas con respecto a lo normal, en buena parte de las mitades norte y este de la Península, y especialmente en provincias de Castilla y León, el número de días de tormenta fue muy superior al habitual, sobre todo en primavera. Así, entre el 15 de marzo y el 30 de abril, todos los días, excepto el 4 de abril, hubo tormenta en algún punto de la península ibérica.

El hecho de que en dos de los meses en los que la caída de rayos es más habitual (septiembre y octubre) se registrasen muy pocas tormentas en 2020, y que en meses fríos, como enero, marzo y abril, no demasiado propicios a las tormentas, hubiese un número elevado de estas, explica por qué el número anual de días de tormenta ha sido tan elevado (muchas tormentas en invierno y primavera, pero en general con un número de descargas no muy elevado), mientras que el número total de descargas ha estado por debajo de la media (pocos fenómenos tormentosos en septiembre y octubre, cuando habitualmente en esas fechas las tormentas llevan asociadas una gran cantidad de descargas).

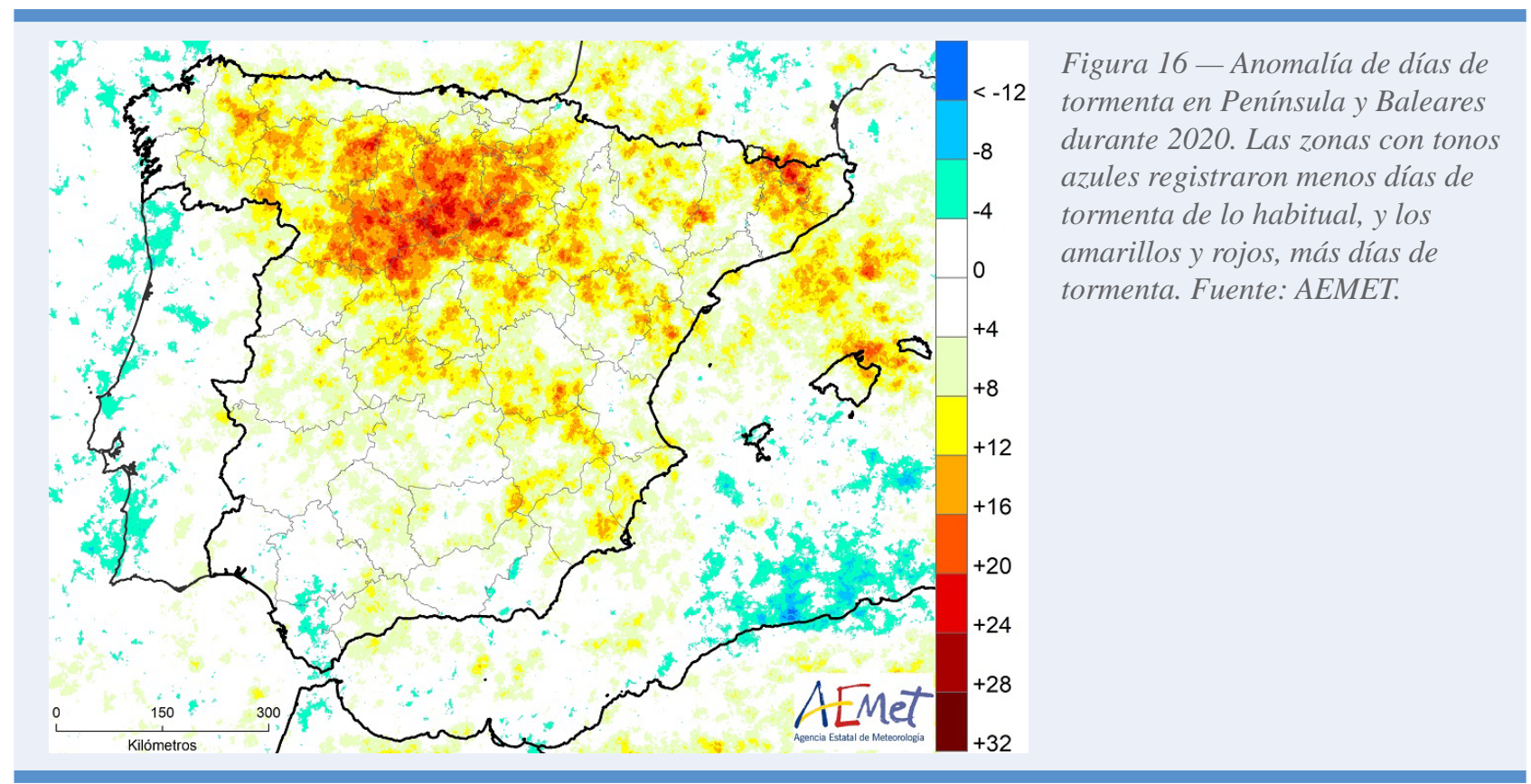




\section{FENÓMENOS METEOROLÓGICOS Y CLIMÁTICOS EXTREMOS}

Los fenómenos meteorológicos y climáticos extremos tienen un gran impacto social, pues dado su carácter extraordinario y gran intensidad, pueden producir daños en bienes y personas. Como episodios extremos más destacados en 2020, cabría señalar el temporal asociado a la borrasca Gloria en enero en el área mediterránea, la importante llegada de polvo en suspensión a Canarias procedente del continente africano en febrero, o la ola de calor que tuvo lugar entre el 25 de julio y 2 de agosto, la tercera más larga desde 1975. Además, 2020 fue el año más cálido de la serie en España, junto con 2017. En las figuras 17 y 18 se señalan los episodios más importantes acaecidos a lo largo del año en España desglosados, respectivamente, por meses y por zonas.

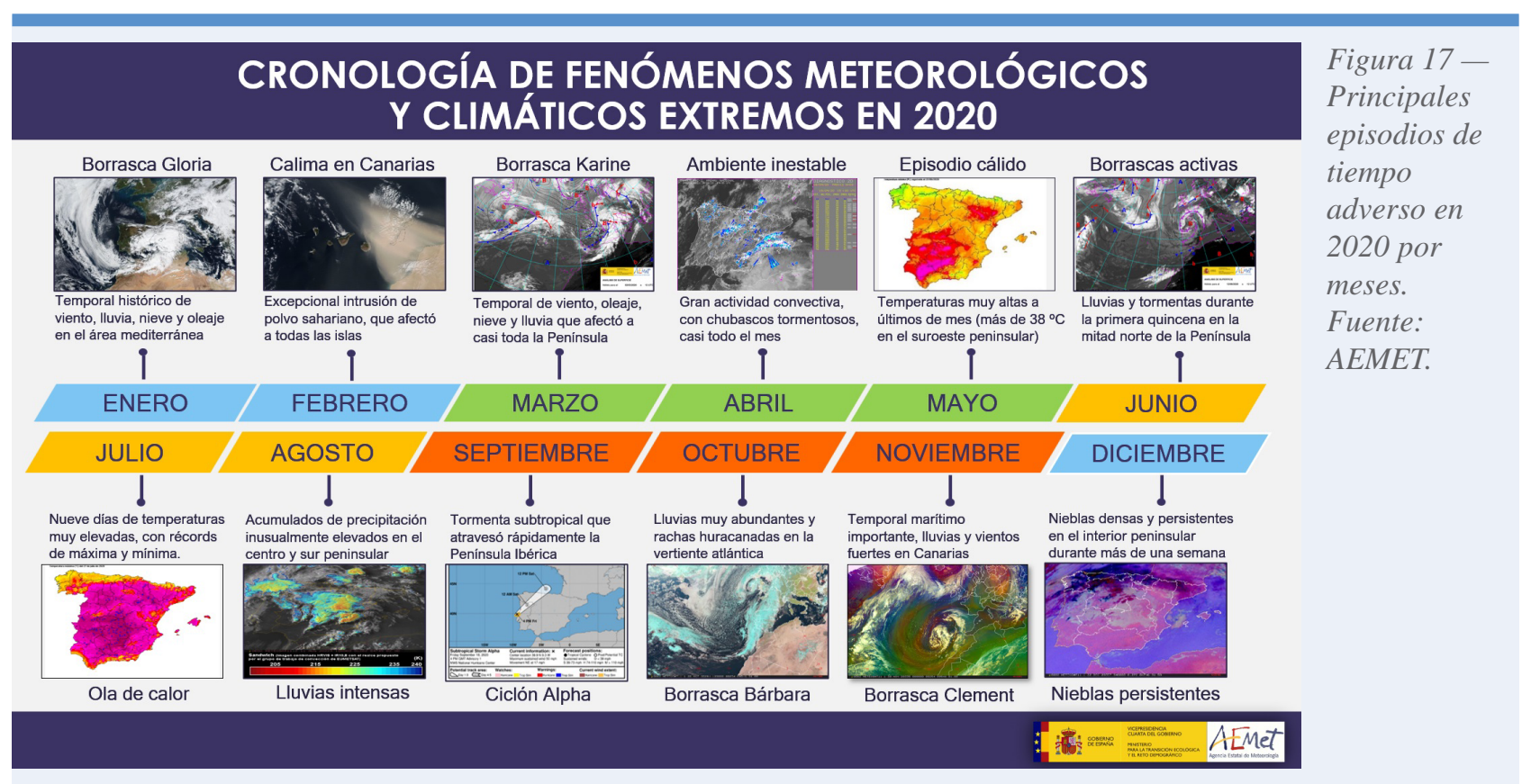

Figura 18-Principales episodios de tiempo adverso en 2020 por lugar de ocurrencia. Fuente: AEMET.
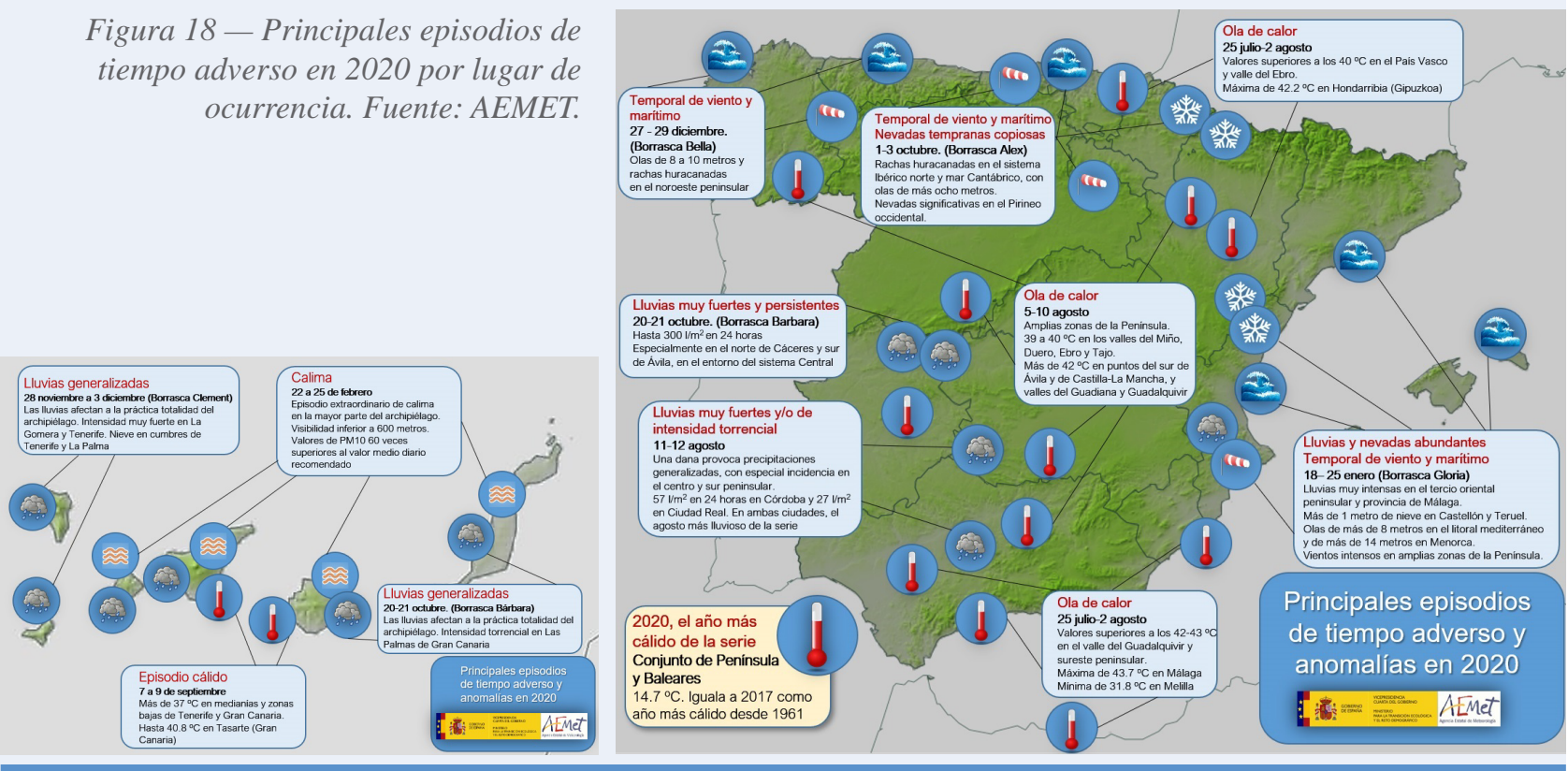


\section{PATRONES CLIMÁTICOS PREDOMINANTES A LO LARGO DE 2020}

La sucesión de los diferentes patrones climáticos establecidos a lo largo de 2020 condicionó los tipos de tiempo registrados en nuestro entorno geográfico. A continuación, se detallan los patrones que mayor importancia cobraron a lo largo de las estaciones.

\section{INVIERNO}

El invierno meteorológico compuesto por los meses de diciembre de 2019 y enero y febrero de 2020 fue extremadamente cálido (se trató del invierno con mayor temperatura media desde 1961) y con precipitaciones ligeramente inferiores a la media, lo que concuerda con el hecho de que, a lo largo de la estación, la presión atmosférica fue en promedio más alta de lo normal en la cuenca mediterránea occidental, incluyendo la península ibérica y Baleares.

Este tiempo anticiclónico estuvo asociado a la fase positiva de la AO (Artic Oscillation), un patrón relacionado con la intensidad de los vientos del oeste en latitudes medias. En general, cuando el vórtice polar estratosférico está fuerte, la $\mathrm{AO}$ tiende a fases positivas. En el invierno 2019-2020, el mencionado vórtice polar fue excepcionalmente intenso y persistente, favoreciendo que el aire frío quedase confinado en el Ártico. Así, tuvo lugar una fase positiva de la AO sin precedentes desde 1950 en cuanto a su magnitud.

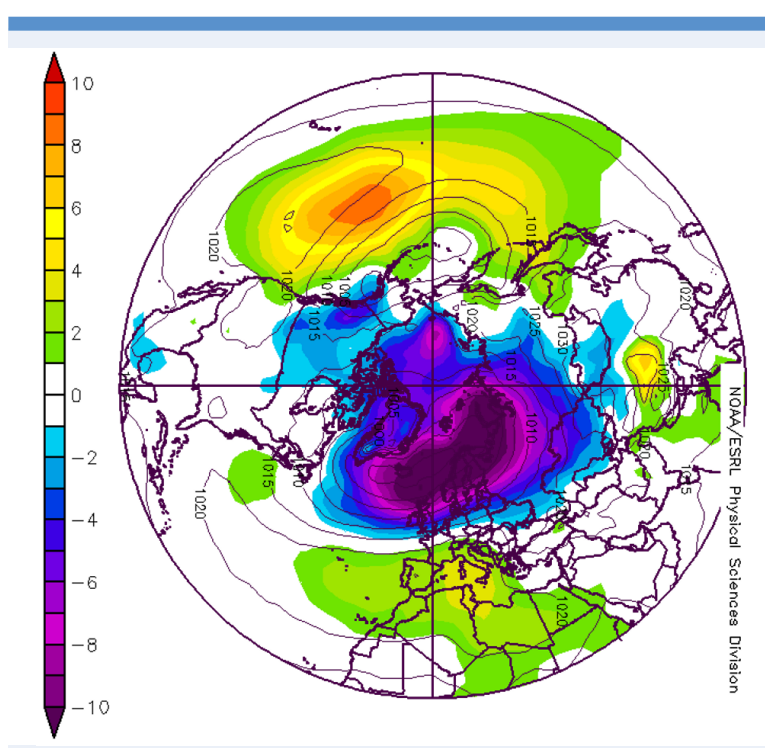

Figura 19 - Promedio para el invierno 2019-2020 de la presión a nivel del mar (líneas) y sus anomalías (color) en hPa. En este mapa y los siguientes, los tonos fríos indican anomalías negativas (en este caso, presiones inferiores a lo normal); los tonos cálidos, anomalías positivas. Fuente: NOAA.

\section{PRIMAVERA}

La primavera climatológica (meses de marzo, abril y mayo), fue en 2020 muy cálida (especialmente por unas temperaturas nocturnas muy altas) y muy húmeda. En ambos casos, la abundante nubosidad jugó un papel destacado. No en vano, se trató de una primavera con muy

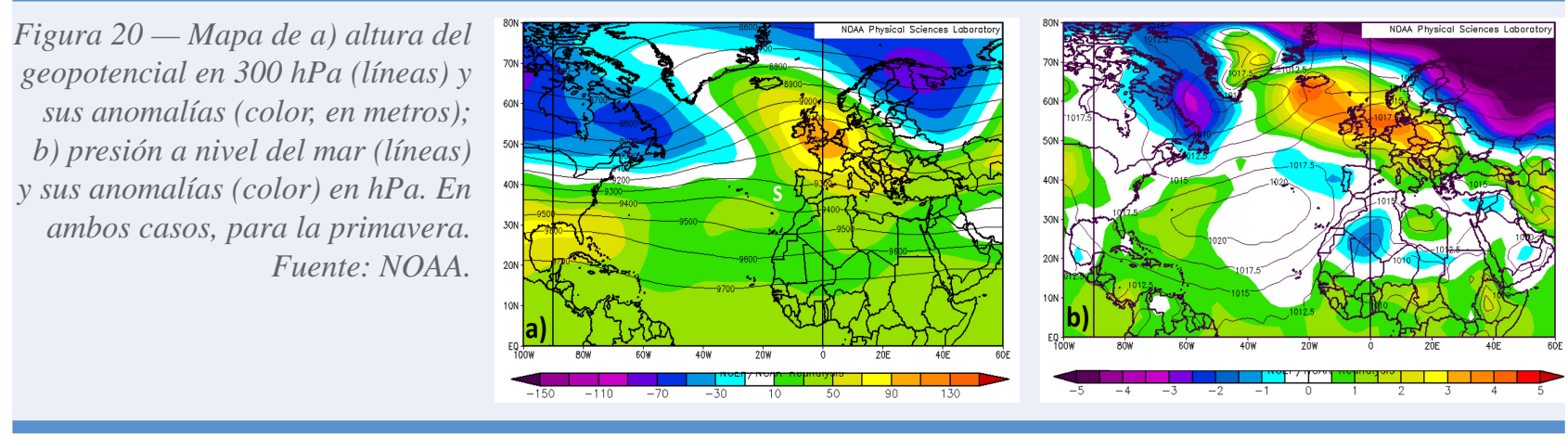


pocas horas de sol, justo lo contrario que lo que ocurrió en el norte y centro de Europa, donde la primavera fue muy seca y excepcionalmente soleada en países como el Reino Unido y Bélgica.

Esto se explica por el hecho de que lo largo de la estación predominó un patrón de bloqueo anticiclónico europeo (las presiones fueron más altas de lo normal en el norte de Europa), que obligó a las borrascas a desviarse de su trayectoria habitual y a circular por latitudes más bajas. Así, las presiones al oeste de la península ibérica fueron inferiores a las normales. Además, en la zona del Sahel africano se produjeron más lluvias de las habituales en la estación primaveral, lo que propició unas condiciones más húmedas en la atmósfera cuya influencia se sintió en nuestro entorno, ayudando a una mayor presencia de nubosidad. Se puede hablar, pues, de una interacción tropical-extratropical.

\section{VERANO}

La estación estival estuvo marcada en el hemisferio norte por las temperaturas excepcionalmente altas en el norte de Siberia. En Europa y en España el verano fue muy cálido, especialmente en la mitad sur de la península ibérica, donde hubo más de 40 días en situación de «estrés por calor muy fuerte» según el Índice Climático Térmico Universal. El mes de julio fue el tercero más cálido de la serie en nuestro país, teniendo un carácter extremadamente cálido en amplias zonas del sur peninsular como consecuencia de la persistencia de los vientos de levante y las temperaturas claramente superiores a las normales en niveles altos de la troposfera.
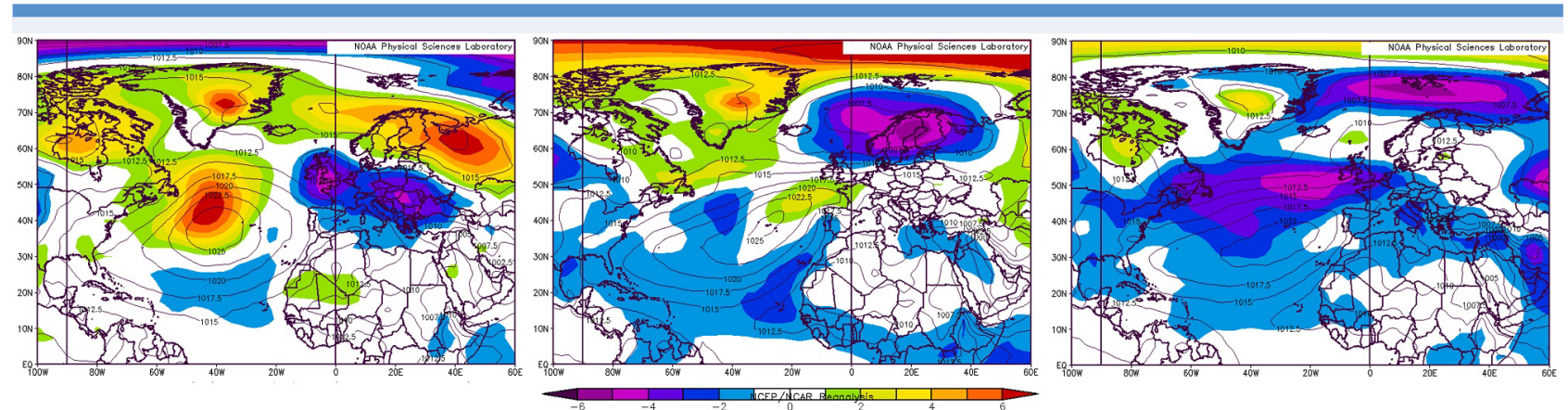

Figura 21 - Presión a nivel del mar (líneas) y sus anomalías (colores) para los meses de junio, julio y agosto de 2020 en hPa. Fuente: NOAA.

Durante el verano tuvo lugar un reforzamiento de «La Niña», que provocó temperaturas más bajas de las normales en las aguas del Pacífico oriental y central en latitudes tropicales. Este fenómeno suele ir acompañado de una intensificación de las lluvias monzónicas en el sur de Asia, como así ocurrió en 2020. Se registraron precipitaciones muy intensas que provocaron un calentamiento anómalo de las capas altas de la troposfera en Asia meridional, al liberarse gran cantidad de calor latente por condensación del vapor de agua. Es posible que estas temperaturas más altas de lo normal en capas altas se extendieran hacia el oeste, alcanzando la península ibérica y favoreciendo el carácter muy cálido de julio, junto con factores locales como la fuerte insolación y la mencionada alta frecuencia de vientos de levante, impulsados por la presencia de bajas presiones sobre el Atlántico, al suroeste de Portugal. 


\section{OTOÑO Y DICIEMBRE}

Las temperaturas del otoño de 2020 fueron superiores a las habituales tanto en España como en el resto de Europa. Fue una estación más seca de lo normal en Europa occidental, incluyendo la mitad oriental de la Península y el archipiélago balear. El mes de diciembre tuvo, en cambio, un comportamiento normal en nuestro país. La intensa actividad ciclónica tropical a lo largo del otoño pudo haber influido en el carácter climático de la mencionada estación en nuestras latitudes.

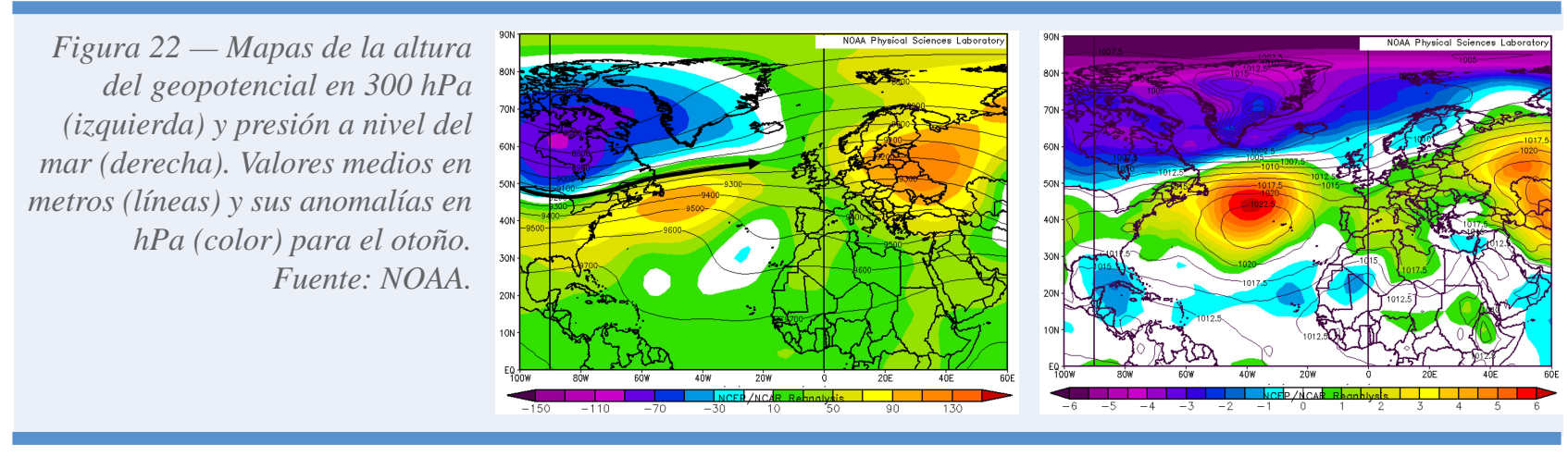

Y es que la extremadamente activa temporada de huracanes del Atlántico, con un récord de 30 ciclones tropicales con nombre, produjo sobre el Atlántico una dorsal anómala, es decir, presiones más altas de lo normal que obligaron a la corriente en chorro que transporta las borrascas de oeste a este a circular por latitudes más altas que las nuestras. Aun así, hubo descensos temporales de latitud de la corriente en chorro, aspecto que se vio reflejado en la llegada de un total de seis borrascas de gran impacto a nuestro entorno entre los meses de septiembre y diciembre. 
A Emet 